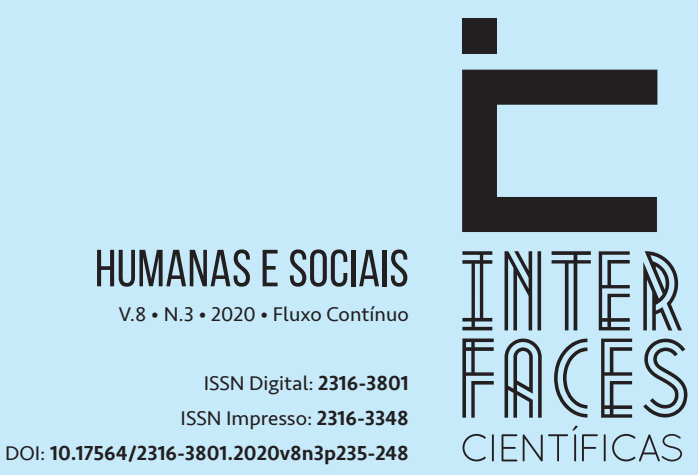

\section{PRECARIZAÇÃO DO TRABALHO: ASPECTOS CONJUNTURAIS, FUNDAMENTOS DE SUA GÊNESE E TENDÊNCIAS CONTEMPORÂNEAS}

PRECARIOUSNESS OF WORK: CONJUNCTURE ASPECTS, FUNDAMENTALS OF ITS GENESIS AND CONTEMPORARY TRENDS

PRECARIEDAD LABORAL:ASPECTOSDELA CONJUNTURA, FUNDAMENTOSDESUGENESIS Y TENDENCIAS CONTEMPORARIAS

\section{RESUMO}

Este artigo é um estudo teórico a respeito da precarização do trabalho no contexto histórico contemporâneo. Inicialmente, partimos de uma análise que prioriza o aspecto conjuntural como fundamento da precarização. Essa intepretação encontra-se, principalmente, nas obras dos autores Robert Castel e Guy Standing. Em seguida, buscamos examinar a partir de uma perspectiva marxista quais os elementos que estão na gênese da precarização, dando ênfase a explicação contida no capítulo XXIII de $O$ capital, na Lei geral da acumulação capitalista. Por último, apresentamos uma síntese das atuais tendências presentes nas relações de produção, em que a precarização aparece como uma realidade crescente em todo mundo e nos diferentes setores econômicos, manifestada sob diferentes formas de inserção dos trabalhadores em relações marcadas pela fragilidade de vínculos e pela incerteza.

\section{PALAVRAS-CHAVE}

Acumulação Capitalista. Precarização do Trabalho. Relações de Produção. 


\section{ABSTRACT}

This article is about a theoretical study about the precariousness of work in the contemporary historical context. Initially, we start with an analysis that prioritizes the conjunctural aspect as the foundation of precariousness. This interpretation is found mainly in the works of authors Robert Castel and Guy Standing. Next, we seek to examine from a Marxist perspective, which elements are in the genesis of precariousness, emphasizing the explanation contained in chapter XXIII The Capital, in the General Law of capitalist accumulation. Finally, we present a synthesis of the current trends in production relations, in which precariousness appears as a growing reality throughout the world and in the different economic sectors, manifested under different forms of insertion of workers in relationships marked by the fragility of ties and by the uncertainty.

\section{KEYWORDS}

Capitalist Accumulation. Work Precariousness. Production Relations.

\section{RESUMEN}

El presente texto se trata de un estudio teórico acerca de la precariedad laboral en el contexto histórico contemporáneo. Inicialmente, partimos de un análisis que prioriza el aspecto coyuntural como fundamento de la precariedad. Esta interpretación se encuentra principalmente en las obras de los autores Robert Castel y Guy Standing. A continuación, buscamos examinar desde una perspectiva marxista cuáles son los elementos que están en la génesis de la precarización, dando énfasis a la explicación contenida en el capítulo XXIII de El capital, en la Ley general de la acumulación capitalista. Por último, presentamos una síntesis de las actuales tendencias presentes en las relaciones de producción, en que la precariedad aparece como una realidad creciente en todo el mundo y en los diferentes sectores económicos, manifestada bajo diferentes formas de inserción de los trabajadores en relaciones marcadas por la fragilidad de vínculos y por la incertidumbre.

\section{PALABRAS CLAVE}

Acumulación capitalista. Precariedad laboral. Relaciones de producción. 


\section{INTRODUÇ̧̃̃o}

A partir de meados da década de 1970 o capitalismo monopolista entrou em uma nova fase. Após trinta anos de contínuo crescimento, uma intensa crise atingiu globalmente a economia, provocando amplas repercussões em vários espaços da vida social (ANTUNES, 2009). Se durante os trinta anos que precederam esse colapso, a Europa havia vivenciado uma melhoria das condições de vida dos trabalhadores, em especial pela ampliação de direitos sociais, pelo aumento de políticas públicas, pelo crescimento da massa salarial e pelo maior acesso ao consumo, a partir dos anos 1970 esse quadro sofreu uma grave alteração.

A severidade da crise e a intensidade das lutas de classe, foram fatores que contribuíram de forma decisiva para que os grupos monopolistas buscassem soluções adequadas para manutenção de um fluxo de valorização de valor adequado ao seu movimento expansionista, porém, tendo que encarar limites mais estreitos para sua realização. As ações de resposta para enfrentamento das próprias contradições do capital e a organização política dos trabalhadores, trataram de impor formas de dominação social que incorporassem alterações na esfera da produção, financeira, política e ideológica. Nesses termos a aplicação do receituário liberal foi pautado por um frontal ataque ao trabalho.

O conjunto de ações que acompanham essa ofensiva foi diverso, podendo ser sinteticamente indicados a partir dos seguintes aspectos: emergência do desemprego estrutural; intensas mudanças tecnológicas; crescimento dos níveis de informalidade; ampliação do trabalho feminino; intensificação do ritmo das jornadas de trabalho; retirada de direitos trabalhistas; descolamentos espaciais na produção; mudanças nas formas de gestão da força de trabalho; novas exigências de qualificação; fragmentação das lutas dos trabalhadores e o fenômeno contemporâneo da precarização do trabalho etc.

Sobre esse último aspecto, as primeiras definições sobre a precarização do trabalho contemporâneo tiveram sua gênese na sociologia francesa a partir do final da década de 1980 (STANDING, 2013). Contudo, alguns de seus principais intérpretes vão desenvolver seus estudos no decênio seguinte. Robert Castel (2009) e, mais recentemente, Guy Standing (2013), entendem que esse fenômeno se traduziria, principalmente, pela flexibilização de direitos trabalhistas, pelo aumento do desemprego e pelo crescimento da insegurança social.

Em resumidas palavras, o esgotamento e a desagregação do binômio fordista/keynesiano teriam provocado transformações nas relações de produção2 em escala mundial, não poupando sequer os trabalhadores europeus. 0 resultado é que esse processo de mudanças econômicas e políticas seria a causa da erosão acelerada do trabalho regulamentado, herdeiro do taylorismo/fordismo, que predominou durante boa parte do século passado, sendo substituído por formas de trabalho precarizadas.

Na esteira das mudanças econômicas e políticas desencadeadas já a partir do final da década de 1970, Castel (2009) e Standing (2013) expressam que ao contrário do padrão de “salariado 3” presente

2 Utilizamos o termo "relações de produção" para indicar aquilo que vários autores contemporâneos costumam chamar de "mundo do trabalho". Nossa intenção é apenas manter o rigor teórico das categorias marxianas, ainda que não vejamos nenhum problema grave no termo "mundo do trabalho".

3 Braga (2013, p. 15), explica que esse termo se refere a "classe de trabalhadores assalariados cuja reprodução é regulada pelos direitos de cidadania". 
nos trinta anos após a segunda guerra, o desmonte do padrão fordista e o desmanche das formas de proteção estatal provocava um ampliado e acelerado processo de insegurança social. Conforme Standing (2014, p. 13): “Se durante a Grande Transformação, o capital industrial nacional se propunha habituar o núcleo do proletariado a um trabalho e a uma vida de estabilidade, hoje o capital global pretende habituar o precariado a um trabalho e a uma vida de instabilidade".

O novo horizonte de incertezas para os trabalhadores estaria aportado nas emergentes formas de assalariamento, na sua heterogeneidade, no crescimento do trabalho temporário, no trabalho subcontratado, part-time, na terceirização, na desregulamentação de direitos etc. Diante dessas mudanças, estaria surgindo uma nova classe, que seria uma espécie de subproduto da crise fordista, intensificada pelo ataque neoliberal: o precariado.

\section{A PRECARIZAÇÃO DO TRABALHO EM CASTEL E STANDING}

Em 1995, Robert Castel lançou o livro As Metamorfoses da Questão Social. Parte importante de sua abordagem é baseada na análise da condição do assalariamento ao longo da dinâmica capitalista. Ao examinar as recentes condições dos “assalariados”, postas em ação a partir de meados da década de 1970, observa os impactos causados pelo aumento do desemprego e a multiplicação de formas de trabalho temporárias e precárias. Essa situação levava os trabalhadores a um patamar de incertezas e um futuro que o próprio autor caracteriza como "marcado pelo selo do aleatório" (CASTEL, 2009, p. 21).

Nessa conjuntura desfavorável para os trabalhadores, a condição salarial encontrava-se sob o choque da presença daquilo que o autor denomina de "supranumerários inempregáveis". Tratava-se, portanto, da existência de uma massa extensa de indivíduos que além de desempregados ou de em subempregos, também não teriam o suporte das clássicas formas de proteção e segurança social.

Nesse sentido, o cenário contemporâneo do trabalho estaria configurado pela vulnerabilidade, pela fragilização de conquistas sociais e a desagregação de estatutos para os trabalhadores, que antes eram assegurados. Diante desse quadro, o agravamento das tensões sociais seria uma consequência inevitável das transformações nas relações de produção, resultado de uma industrialização selvagem (CASTEL, 2009).

Ainda de acordo com o autor, essa situação de vulnerabilidade social a qual estavam submetidos os trabalhadores a partir das transformações capitalistas na última quadra do século XX, representaria uma mudança consubstancial com relação a situação vivida nas décadas precedentes a esse período, notadamente entre o final da segunda guerra até 1975.

Até chegar às mudanças ocorridas nas relações entre capital e trabalho nas últimas décadas do século passado, Castel (2009) percorre um longo percurso para explicar a condição do trabalho assalariado. Conforme argumenta, antes da consolidação da sociedade capitalista, as formas de venda "livre” da força de trabalho já eram presentes, sendo representadas por:

Companheiros de ofícios, uma espécie de trabalhador muito qualificado;

Mestres rebaixados ou arruinados, que eram reduzidos a trabalhar para um terceiro ou, normalmente, para um comerciante; 
Chambrelans, que trabalhavam e não possuíam lojas;

Forasteiros, que buscavam se estabelecer por contra própria; assalariados domésticos e serviçais;

Os assalariados de serviços administrativos, escreventes dos tribunais, caixeiros de loja etc.;

Trabalhadores que não tiveram nenhum tipo de formação e atuavam na construção, carregando mercadorias, biscateiros, sempre dispostos para qualquer tipo de serviço que apareça;

Um subproletariado, vivendo no meio rural trabalhando em atividades domésticas ou com ocupações sazonais; o agricultor parcelar que mesmo tendo um lugar fixo, se vê obrigado a complementar seus recursos com atividades artesanais; os operários camponeses, ainda que seu número seja relativamente pequeno;

Os trabalhadores sazonais, vivendo principalmente em pequenas vilas e aldeias; e finalmente, o proletariado nascente das manufaturas e primeiras indústrias.

Ao tratar do capitalismo consolidado, já se referindo a uma sociedade industrial, Castel (2009) entende que o assalariamento se caracteriza por três etapas fundamentais: a condição proletária, condição operária e a condição salarial. A condição salarial seria a detentora de maiores direitos protetivos e de estabilidade. Porém, de acordo com o autor, essa condição passou a ser corroída a partir do desmonte do padrão fordista/keynesiano. Partindo da realidade francesa, mas apontando a tendência da precarização como crescente, Castel sintetiza a esses novos trabalhadores precarizados nos seguintes moldes:

A presença, aparentemente cada vez mais insistente, de indivíduos colocados em situação de flutuação na estrutura social e que povoam seus interstícios sem encontrar aí um lugar designado. Silhuetas incertas, à margem do trabalho e nas fronteiras das formas de troca socialmente consagradas - desempregados por período longo, moradores dos subúrbios pobres, beneficiários de renda mínima de inserção, vítimas das readaptações industriais, jovens à procura de emprego e que passam de estágio a estágio, de pequeno trabalho à ocupação provisória. (2009, p. 23).

Esse novo cenário e suas correspondentes formas de trabalho e inserção social seriam antípodas em relação à condição dos assalariados estáveis. Na condição salarial, a maioria dos trabalhadores tinha sua inserção social a partir do lugar que ocupavam no salariado, não somente sobrevivendo de uma renda, mas amparados por formas de proteção social e de inserção estável no mercado de trabalho.

Na nova configuração das relações de produção, a precarização é compreendida como um processo nuclear das novas tendências na esfera do trabalho, comandada por exigências conjunturais econômicas, políticas e tecnológicas. Castel (2009) ainda considera gravidade desse quadro, pois essa condição precária deixava de ser uma situação excepcional ou um estágio provisório, tornando-se de forma crescente uma prática permanente.

O núcleo da tese de Castel encontra-se em apresentar o fenômeno da precarização do trabalho como sendo essencialmente o resultado de uma determinada conjuntura histórica. Destaca ainda que as transformações contemporâneas nas condições de vida dos trabalhadores impulsionam um novo quadro qualitativo para o trabalho, com significativa piora nas condições de vida para o trabalhador. 0 processo de ganhos obtidos pelos trabalhadores durante as três décadas após a segunda guerra 
foi interrompido pela "onda" neoliberal, modificando essa trajetória ascendente e impossibilitando a construção de uma sociedade mais aberta, mais acolhedora ou menos desigual (CASTEL, 2009).

Além de Castel, outro autor europeu tem se destacado no estudo da temática da precarização do trabalho, trata-se do inglês Guy Standing. 0 autor é ex-diretor da Organização Internacional do Trabalho (OIT) e um dos responsáveis pela criação do índice de trabalho decente, da OIT. O recente livro de Standing (2013), Precariado, a Nova Classe Perigosa, além de ser um sucesso editorial internacional, também trouxe uma gama de polêmicas, em especial no tocante a abordagem que o autor britânico faz ao tratar dos riscos políticos do precariado.

A abordagem que Standing realiza segue em demonstrar que a emergência dessa nova classe - o precariado -, não se expressa de forma análoga ao proletariado tradicional, nem representa uma similitude com as classes médias superexploradas. A teoria que Standing concebe é que de uma certa maneira, o precariado seria o filho indesejado do casamento do neoliberalismo com a globalização do capital (BRAGA, 2014). Nesse sentido, refletiria um fenômeno recente, consequência das implicações econômicas e políticas da reestruturação produtiva e do avanço neoliberal, respectivamente.

Com a ampliação da precarização por todo mundo, os argumentos de Standing (2013) apontam para o surgimento de uma nova classe, definida fundamentalmente pela insegurança laboral e pela carência de uma identidade com o trabalho, em contraposição ao que ocorrera com os operários na era de ascensão fordista. Diante disso, Standing (2013) entende que essa classe seria dividida entre os grupos de indivíduos frustrados e revoltados. Um traço comum aos dois grupos é o de estarem marcados por um grau de descontentamento, o que os torna incapazes de reconhecer a dimensão de classe a qual pertence.

Não sendo ainda uma classe para si, estando negadas as possibilidades de elevação social e de melhoria em sua condição de vida, o resultado é que o precariado estaria também mais suscetível as manobras ideológicas da extrema direita. Como a precarização do trabalho se ampliou nas formas manifestação e na amplitude de sua incidência também nos países centrais, o crescimento de grupos de extremistas neofascistas na Europa já seria um claro indicativo desses riscos.

Um aspecto que consideramos relevante para nossa reflexão é que como o autor também considera que a existência do precariado seria derivada da ofensiva neoliberal, por conseguinte, a situação de precarização possuiria, tal qual como interpretado antes por Castel (2009), uma relação direta com a conjuntura histórica recente. Com isso, é apropriado considerar que autor não vincula a precarização do trabalho com a lógica em si do capitalismo em todo seu processo histórico. A própria vinculação do processo de precarização com as políticas neoliberais forma um quadro indicativo da compreensão histórica conjuntural que Standing (2013) adota ao analisar a precarização do trabalho.

\section{A GÊNESE DA PRECARIZAÇ̃̃O DO TRABALHO, NUMA PERSPECTIVA MARXISTA}

Do ponto de vista dos aparatos teóricos necessários à compreensão dos fundamentos da precarização do trabalho, a parte essencial da obra de Marx que examina a gênese da precarização está na Lei geral da acumulação capitalista, exposta no capítulo XXIII de O Capital. Na análise contida nesse capítulo, 
as formas de precarização não são tratadas como um produto originário meramente da ação do Estado ou de uma conjuntura determinada. Com isso, Marx assinala que é no exame a dinâmica da estrutura econômica da sociedade capitalista, que se encontra o elemento-chave para esse entendimento.

O movimento de acumulação descrito por Marx (1996) revela que a apropriação privada de riqueza e a acumulação de capital são partes do movimento que causa o pauperismo. Mesmo que a dinâmica de acumulação tenha passado por enormes transformações e ainda que não sejam fenomenicamente iguais, em relação àquelas vistas pelos olhos de Marx no século XIX, tais mudanças não desfizeram nem diluíram sua lógica mais profunda.

No capítulo da Lei geral da acumulação capitalista, Marx (1996, p. 275) expõe a contradição e a lógica que rege esse processo: "A acumulação da riqueza num polo é, portanto, ao mesmo tempo, a acumulação de miséria, tormento de trabalho, escravidão, ignorância, brutalização e degradação moral no polo oposto, isto é, do lado da classe que produz seu próprio produto como capital”.

A acumulação capitalista é incessantemente impulsionada pela voracidade que a velocidade de seu movimento the exige. Seu impulso para a ampliação contínua empurra as personificações do capital a encontrarem à sua disposição trabalho abstrato, força viva que valorize o valor. 0 interesse não é tão somente o de produzir um valor de uso, mas pôr em movimento o capital disponível para a aquisição de mercadorias - entre elas, a força de trabalho, para que em seguida ocorra a produção de uma nova mercadoria. Entretanto, o trajeto percorrido pelo capital não se esgota nesse instante da produção, pois precisa desaguar na circulação é lá que a mais-valia será realizada. Por isso, todas as formas concretas de trabalho devem estar submetidas a uma única: trabalho humano abstrato.

Mas a obtenção das condições de acesso aos bens necessários ao trabalhador depende de mediações que são externas à sua vontade; essas passam necessariamente pelos condicionantes postos pelo mercado de trabalho (CEOLIN, 2014). Qual tipo de emprego o trabalhador irá conseguir, se é que o terá, ou sob que condições ele trabalhará, são questões que não dependem puramente do esforço ou do querer do trabalhador.

Sob o impulso da mudança na composição orgânica do capital, o desemprego e a precarização do trabalho são elementos próprios ao processo de acumulação, fazendo parte de uma mesma gênese. Desde as últimas décadas do século XX, os dois fenômenos têm se ampliado, o desemprego ganhando o status de estrutural e a precarização se consolidando como uma tendência crescente (ANTUNES, 2009).

0 processo de acumulação de capital, além de ser a gênese do desemprego e a da precarização, também produz necessariamente uma tendência para queda nas taxas de lucratividade, o que por sua vez, impulsiona o estabelecimento em sua própria dinâmica também de estratégias para atenuar essa tendência. A tendência de diminuição nas taxas de lucratividade é provocada pelo mecanismo que busca sua elevação, revelando o caráter insanável das contradições do capital.

A questão é que a produção do valor é obtida e "determinada pela quantidade de trabalho humano abstrato socialmente necessário” (IASI, 2010, p. 29). Assim sendo, esse valor apenas pode existir se houver o consumo da força de trabalho. 0 problema é que a diminuição do uso da força de trabalho por meio da modificação da composição orgânica do capital e a maior utilização de capital constante em relação à variável - acaba sendo um elemento impulsionador da tendência de queda nas taxas médias de lucratividade. 
Ao escrever o volume três de O Capital, em seu capítulo XIV, Marx (1984) busca analisar quais as estratégias que os capitalistas se utilizam para enfrentar a tendência à queda nas taxas de lucratividade, elencando seis possibilidades ${ }^{4}$. Entre essas, chamamos atenção para a elevação do grau de exploração do trabalho, a compressão do salário abaixo de seu valor e o aumento da superpopulação relativa (MARX, 1984).

Trata-se de respostas que o movimento de acumulação de capital necessita utilizar-se para enfrentar os obstáculos da tendência à queda nas taxas de lucratividade. Contextualizando tal análise para entender a precarização do trabalho - enquanto síntese de outros fenômenos - nos parece que a precarização é a expressão de funcional para enfrentar à tendência de queda nas taxas de lucratividade.

\section{A PRECARIZAÇÃO COMO TENDÊNCIA CRESCENTE}

Tal qual a própria sociedade capitalista, movida por constantes e rápidas transformações, a "precariedade" também passou por uma metamorfose, mesmo que guarde traços de seu passado jamais superado. No conjunto das intensas mudanças por que o capitalismo contemporâneo vem passando nas últimas décadas, a "precariedade" se transformou num processo de precarização do trabalho que domina mundialmente a dinâmica das relações de produção. Essa condição, revela um novo grau qualitativo nas formas de precarização do trabalho. Sob o lema da flexibilização, a precarização vai se mostrando tendencialmente crescente em todo mundo, atingindo empresas públicas e privadas, se manifestando em todos os setores da economia.

A premissa defendida pelo receituário liberal é da flexibilização, da rejeição quanto à regulamentação. Assim, considera que todo limite à expansão do livre metabolismo do capital deve ser rejeitado. Mas, diferentemente do discurso liberal, o que a realidade das relações de produção tem demonstrado é um quadro de piora para os trabalhadores, inclusive nos países centrais (ANTUNES, 2009). $\mathrm{Na}$ prática, tais regras apenas expressam uma tentativa de melhorar as condições de acumulação de capital, de garantia de seu ciclo expansivo, à custa da precarização do trabalho.

A respeito do processo de "flexibilização", Harvey argumenta que tem sido uma tendência no mercado de trabalho global diminuir o "número de trabalhadores 'centrais' e empregar cada vez mais uma força de trabalho que entra facilmente e é demitida sem custos quando as coisas ficam ruins" (HARVEY, 2002, p. 144). Para o trabalhador, a flexibilidade tem significado essencialmente mais insegurança e uma piora nas suas condições de trabalho e de saúde.

Os fenômenos da precarização e da flexibilização se encontram frequentemente associados. Mészáros (2007) sustenta que a flexibilização do trabalho, que deve ser facilitada e aplicada "por meio de vários tipos de 'desregulamentação', equivale, na realidade, à implacável precarização da força de trabalho" (2007, p. 148).

4 A seis possibilidades elencadas por Marx (1984) no terceiro volume de 0 Capital, pensadas a partir da dinâmica econômica própria da segunda metade do século XIX são: a elevação do grau de exploração do trabalho, a compressão do salário abaixo de seu valor, o barateamento dos elementos do capital constante, o aumento da superpopulação relativa, a ampliação do comércio exterior e, por fim, o aumento do capital por ações. 
A "flexibilização", tem se estabelecido como uma matriz ordenadora de diversas alterações nas relações de produção. Particularmente para os trabalhadores, ela expressa uma retração "drástica das fronteiras entre atividade laboral e espaço da vida privada, no desmonte da legislação trabalhista, nas diferentes formas de contratação da força de trabalho e em sua expressão negada, o desemprego estrutural" (ANTUNES, 2009, p. 412).

Ao tratar sobre a "flexibilidade" nas relações de trabalho, os Estados têm feito alterações nas legislações para facilitar a aquisição da força de trabalho com o menor custo e o mínimo risco possível. Como exemplo tendencial, a terceirização tem sido uma das estratégias mais comuns. No que se refere à sua ampliação generalizada, há um aspecto instigante e revelador sobre a dinâmica do atual processo de acumulação, suas debilidades e tentativas de soluções, necessariamente paliativas. Em geral, a terceirização transforma o que era trabalho improdutivo dentro da empresa em trabalho produtivo fora dela, metamorfoseando aquilo que era custo em objeto de lucro.

Porém, estando direcionada a transformar atividades-meio e atividades-fim em áreas terceirizadas, sua lógica tem qualitativamente um aspecto mais brutal, pois revela que sua natureza mais íntima é elevar os níveis de exploração, barateando o custo do trabalho vivo.

Sobre a precariedade do trabalho no contexto histórico contemporâneo, Barbier (apud SÁ, 2010) informa que o termo "precariedade" passou a ser utilizado desde o final da década de 1970, na França. Carvalho, Oliveira e Veloso (2012) assinalam que na década de 1990, a abordagem da "precariedade" na França, Espanha e Itália estava principalmente associada ao fenômeno da instabilidade nos empregos, o chamado trabalho atípico. Isso se relacionava notadamente em razão do crescimento dos contratos de trabalho temporários, cada vez mais frequentes e amplos no continente europeu.

Já na Inglaterra, as autoras mencionam que nesse período, a preocupação com o tema dava-se em decorrência, nomeadamente, dos baixos salários praticados e da piora nas condições de trabalho, sendo essa combinação tratada como bad jobs (CARVALHO; OLIVEIRA; VELOSO, 2012).

Essa combinação entre as incertezas vividas pelo trabalhador no mercado de trabalho com as baixas remunerações salariais passou a ser o elemento principal de análise para entender o fenômeno da precarização do trabalho, que desde o final do século XX passou a ganhar cada vez mais amplitude na Europa. Se o Velho Continente observava esses movimentos com relativa surpresa, a periferia do sistema jamais deixou de ter em suas dinâmicas produtivas a incerteza e os baixos salários como componentes presentes na relação entre capital e trabalho.

Flexibilizar relações de trabalho não significa oferecer mais agilidade em processos e aumento de possibilidades de inserção para trabalhadores. Trata-se, essencialmente, de retirar objetiva e formalmente os mecanismos de defesa proletária. Significa deixar por trabalhadores permanentemente dispostos a aceitar qualquer tipo de inserção no mercado de trabalho. Com isso, criam-se mecanismos para que os trabalhadores não tenham condições de esboçar resistência aos variados métodos de trabalho e controle a que possam vir a ser submetidos.

Por tudo isso, as relações de produção capitalistas no século XXI apontam na direção de uma significativa piora das condições do trabalho em dimensão planetária. As práticas da "flexibilização" resultam efetivamente para o trabalhador num processo de precarização. Junto a isso, também tem 
se desenvolvido um conjunto de ações que objetivam arrancar o quanto possível as formas "estáveis" de trabalho e efetuar a retirada de normas protetivas e sociais ao trabalhador.

Nesse contexto, Vasapollo (2015, p. 45) compreende que "a nova organização capitalista do trabalho é caracterizada cada vez mais pela precariedade, pela flexibilização e desregulamentação, de maneira sem precedentes para os assalariados". No que se refere à gravidade do fenômeno da precarização e suas tendências, Mészáros (2015, p. 33) adverte que "os obstáculos reais enfrentados pelo trabalho, no presente e no futuro próximo, podem ser resumidos em duas palavras: flexibilidade e ‘desregulamentação”'.

Tal movimento não se mostra apenas como um aspecto contingencial passageiro, mas uma lógica tendencialmente inexaurível no interior do metabolismo de acumulação de capital. Mészáros (2015, p. 27, grifo do autor) assinala que o problema não é se "o 'trabalho temporário flexível' vai ameaçar os trabalhadores empregados, mas quando estes, forçosamente, vão vivenciar a precarização".

Na análise das transformações ocorridas na esfera do trabalho, é possível considerar que as tendências contidas apontam para uma condição não apenas de perenidade da precarização e, nesse sentido, inserida como uma lógica incorporada aos imperativos de reprodução do capital; mais que isso, sua dimensão nas últimas décadas galgou o nível de um processo agudo de precarização do trabalho, alcançando um patamar qualitativamente muito mais amplo e degradante para os trabalhadores.

\section{CONSIDERAÇÕES FINAIS}

Do ponto de vista dos determinantes históricos do mundo contemporâneo, entender a complexidade das relações capitalistas em sua atual fase é um enorme desafio para os pesquisadores no campo das ciências sociais. As variadas formas de extração de sobretrabalho tendem a anuviar os fundamentos mais profundos que regem a relação entre capital e trabalho.

Se o capital fosse objeto, não uma relação social, ele desafiaria a física, pois sua lógica possibilitaria a ocupação de "dois corpos" no mesmo espaço. Entretanto, capital não é simplesmente dinheiro, é uma relação social movida por contradições constantemente repostas. No interior de seu ser, riqueza e pobreza são dinâmicas de um processo idêntico. Além disso, seu movimento também estabelece a convivência útil entre o novo e o velho, entre o moderno e o aparentemente ultrapassado.

Diante do conjunto de aspectos econômicos, políticos e históricos tratados e, bem como, das diferentes interpretações sobre a precarização do trabalho, é possível fazer algumas reflexões. A precarização do trabalho pode e deve ser estudada, mas ela não é um fundamento que esclareça a si. É efeito e não causa, é fenômeno e não essência, síntese e não categoria. Com esse pressuposto, compreendemos que o atual debate sobre a precarização é insuficiente e precisa ser redirecionado com a radicalidade própria ao rigor marxiano.

Tal qual a perspectiva adotada por Castel (2009) e Standing (2013), parte significativa desse debate tem se pautado identificar a precarização como resultado de determinações históricas. Ainda que esse pressuposto não esteja em si errado, pois qualquer análise de um fenômeno social precisa ser tratada também a partir de elementos concretos e determinados historicamente, é insuficiente por não incorporar aspectos fundantes ao processo de prezacrização. 
Ao buscar os fundamentos mais profundos sobre a precarização do trabalho, encontramos na lei geral da acumulação capitalista os elementos teóricos que explicitam sua gênese. Na perspectiva marxiana, não há ordenamento capitalista que não esteja fundamentado no constante acúmulo de capital. Essa é uma regra de seu próprio metabolismo, pois seu movimento não se limita apenas a proporcionar que um quantitativo crescente de riqueza fique nas mãos de poucos, já que provoca também reflexos sociais para os trabalhadores.

Para Marx (1996), a acumulação de capital estabelece a necessidade de que o dinheiro inicialmente investido seja repartido em duas partes: capital constante e capital variável. A materialização do capital constante, que se expressa sob a forma de máquinas, prédios, matérias-primas etc., permanece sob a posse do capitalista todo o tempo. Já a força de trabalho, que expressa o capital variável investido, fica sob a posse do capitalista apenas pelo período de trabalho em que foi adquirida (SANTOS NETO, 2013). É na utilização ou no consumo da força de trabalho que o capital investido é valorizado. Exatamente em razão disso, potencializar seu uso o quanto for possível é fator prioritário para o interesse capitalista.

No interior do processo de acumulação de capital, os mecanismos necessários para que o processo de valorização ocorra em escala ampliada sofrem uma modificação na composição orgânica do capital (MARX, 1996). Assim, o movimento que desenvolve a acumulação não ocorre sob as condições de uma base técnica inalterável. Antes, pelo contrário, seu impulso expansivo implica uma elevação no capital constante e uma concomitante diminuição do capital variável. É esse movimento que permite a ampliação de uma massa de trabalhadores, que ou estarão desempregados, ou em condições precárias de trabalho.

Assim, a precarização do trabalho não é necessariamente nova, apesar de manifestar atualmente com características específicas e tendencialmente crescentes. Também não é um elemento velho carregado pela história. Ela é parte essencial do capital porque segue sua lógica, é a contradição entre acúmulo de riqueza e ampliação da pauperização em constante movimento.

Ao escrever a Crítica da Filosofia do Direito de Hegel - Introdução, Marx (2010, p. 151) nos oferece uma brilhante reflexão sobre o sentido de radicalidade, para ele: "ser radical é agarrar a coisa pela raiz". Dessa forma, a radicalidade que se torna imprescindível para compreensão da precarização do trabalho reside em explicitar as bases mais profundas dela, que é movida pela dinâmica de acumulação de capital, pela necessidade encontrar em cada conjuntura histórica mecanismos que possibilitem a expropriação da riqueza produzida do trabalhador, em síntese: pela exploração do trabalho.

As debilidades no debate da precarização do trabalho não residem na irrelevância do tema, mas em razão, principalmente, de sua análise estar sonegando aquilo que é fundamental para compreensão do trabalho assalariado mundo, a relação de exploração entre capital e trabalho. Desta compreensão devem surgir as condições teóricas para compreensão da realidade e as bases para uma ação política.

Nossa compreensão é que a negação da realização humana não está na condição precária do trabalho, ainda que essa tem um impacto profundo sobre a vida de uma massa de trabalhadores. Os limites postos para o desenvolvimento pleno das potencialidades humanas está, sobretudo, na própria existência do trabalho assalariado, seja lá de qual tipo for, portanto, sua superação não é o fim ou atenuação da precarização, mas a radical superação do trabalho assalariado. 


\section{REFERÊNCIAS}

ANTUNES, Ricardo. Os sentidos do trabalho. São Paulo: Boitempo, 2009.

BRAGA, Ruy. A política do precariado - do populismo à hegemonia lulista. São Paulo: Boitempo, 2013.

BRAGA, Ruy. Nova classe perigosa? Blog da Boitempo. Publicado em 14/02/2014 Disponível em: http://blogdaboitempo.com.br/tag/guy-standing/. Acesso em: 25 jun. 2018.

CARVALHO, Luísa; OLIVEIRA, Helena; VELOSO, Luísa. Formas atípicas de emprego juvenil na União Europeia. Sociologia, Problemas e Práticas [on-line]. Publicada em 8 de novembro de 2012. Disponível em: http://spp.revues.org/399. Acesso em: 8 jul. 2017.

CASTEL, Robert. As metamorfoses da questão social: uma crônica do salário. Petrópolis-RJ: Vozes, 2009.

CEOLIN, George Francisco. Crise do capital, precarização do trabalho e impactos no Serviço Social. Serviço Social e Sociedade, São Paulo, n. 118, p. 239-264, abr.-jun. 2014.

HARVEY, David. Condição pós-moderna. São Paulo: Edições Loyola, 2002.

IASI, Mauro. A crise do capital: a era da hipocrisia deliberada. Revista Praia Vermelha, Rio de janeiro, v. 19, n. 1, p. 25-40, jan. 2010.

MARX, Karl. 0 capital. Livro terceiro, tomo 1. São Paulo: Nova Cultural, 1984. Coleção Os pensadores.

MARX, Karl. 0 capital - Crítica da Economia Política. Livro primeiro, tomo 2. São Paulo: Nova Cultural, 1996.

MARX, Karl. Crítica da filosofia do direito de Hegel. São Paulo: Boitempo, 2010.

MÉSZÁROS, István. 0 desafio e o fardo do tempo histórico. São Paulo: Boitempo, 2007.

MÉSZÁROS, István. Desemprego e precarização - um grande desafio para a esquerda. In: ANTUNES, Ricardo (Org.). Riqueza e miséria do trabalho no Brasil I. São Paulo: Boitempo, 2015. p. 27-44.

SÁ, Teresa. Precariedade e trabalho precário: consequências sociais da precarização laboral.

Revista Configurações [on-line], v. 7, 2010, publicado em 18 de fevereiro de 2012. Disponível em: http:// configuracoes.revues.org/203. Acesso em: 23 dez. 2018. 
SANTOS NETO, Artur Bispo. Trabalho e tempo de trabalho na perspectiva marxiana. São Paulo: Instituto Lukács, 2013.

STANDING, Guy. Precariado, a nova classe perigosa. Belo Horizonte: Autêntica, 2013.

STANDING, Guy. O precariado e a luta de classes.

Revista Crítica de Ciências Sociais, n. 103, p. 9-24, maio 2014.

VASAPOLLO, Luciano. 0 trabalho atípico e a precariedade elemento estratégico determinante do capital no paradigma pós-fordista. In: ANTUNES, Ricardo (Org.). Riqueza e miséria do trabalho no Brasil I. São Paulo: Boitempo, 2015. p. 45-57.
Recebido em: 11 de Abril de 2019

Avaliado em: 22 de Abril de 2020

Aceito em: 22 de Abril de 2020

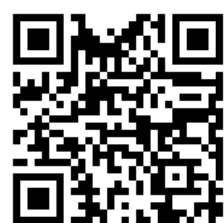

A autenticidade desse artigo pode ser conferida no site https://periodicos. set.edu.br
1 Doutor em Serviço Social pela Universidade Federal de Pernambuco - UFPE; Mestre em Serviço Social pela Universidade Federal de Alagoas - UFAL; Graduado em Comunicação Social; Professor Titular I do Centro Universitário Tiradentes - UNIT. E-mail: albanibrr@hotmail.com

\section{(). (1) (-)}

Este artigo é licenciado na modalidade acesso abertosob a Atribuição-Compartilhalgual CC BY-SA

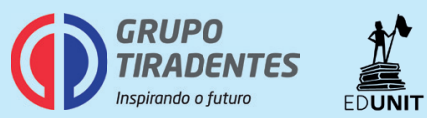


